Revista em Agronegócio e Meio Ambiente, Maringá (PR)

DOI: http://dx.doi.org/10.17765/2176-9168.2017v10n4p1205-1225

\title{
UTILIZAÇÃO DA CINZA LEVE E PESADA DO BAGAÇO DE CANA-DE-AÇÚCAR COMO ADITIVO MINERAL NA PRODUÇÃO DE BLOCOS DE CONCRETO PARA PAVIMENTAÇÃO
}

Sergio Tunis Martins Filho* Carlos Humberto Martins*

RESUMO: A produção excessiva de resíduos agroindustriais sem solução adequada é uma realidade no Brasil, merecendo destaque as usinas sucroalcooleiras, que produzem quantidades consideráveis de cinzas provenientes da queima do bagaço da cana-de-açúcar, utilizado para cogeração de energia elétrica. Sabe-se que o setor da construção civil demanda alta quantidade de materiais cada vez mais escassos e oriundos de processos produtivos com grande geração de gases do efeito estufa. Porém o setor demonstra ter grande potencial para absorver os mais diferentes tipos de resíduos. Objetivou-se investigar a potencialidade de utilização de cinzas provenientes da queima do bagaço de cana-de-açúcar como substituto parcial do agregado miúdo e do aglomerante para produção de concreto utilizado na confecção de blocos para pavimentação, verificando-se a resistência à compressão, abrasão, absorção de água e MEV. Os teores de substituição nos traços foram fixados em $25 \%$ de cinza pesada pelo agregado miúdo e em até $10 \%$ de cinza leve pelo cimento Portland. Para tal, foi realizada a caracterização dos materiais por meio de ensaios físicos e de atividade pozolânica. Verificou-se que uma substituição de $25 \%$ de agregado miúdo por cinza pesada e de $2,5 \%$ de cimento Portland por cinza leve atendeu às recomendações da ABNT NBR 9781:2013.

PALAVRA-CHAVE: Cinzas do bagaço de cana-de-açúcar; Aditivo mineral; Bloco de concreto intertravado.

\section{USE OF LIGHT AND HEAVY ASHES OF THE SUGARCANE BAGASSE AS MINERAL ADDITION IN THE PRODUCT OF CONCRETE BLOCKS FOR STREET PAVING}

\footnotetext{
ABSTRACT: Excessive production of agro-industrial wastes without any proper disposal solution is a constant in Brazil and should be enhanced by sugar-alcohol

Doutorando em Engenharia de Construção Civil pela Universidade Federal do Paraná (UFPR). Docente na Universidade Tecnológica Federal do Paraná (UTFPR), Campus Apucarana, Brasil.

E-mail: sergiotunis@hotmail.com

** Doutor em Engenharia de Estruturas pela USP-São Carlos. Docente Asssociado e pesquisador na Universidade Estadual de Maringá (UEM). Docente do Programa de Pós Graduação em Engenharia Urbana (PEU) da UEM e do Programa de Pós Graduação em Engenharia Civil (PCV) da UEM, Brasil.
} 
plants which produce large amounts of ashes from sugarcane bagasse used in the generation of electricity. Civil construction is notorious for requiring great amounts of material which are becoming rarer and derived from production processes with high production rates of greenhouse-effect gases. On the other hand, civil construction has a great capacity in absorbing different types of wastes. The use of ashes from sugarcane bagasse as a partial replacement of small aggregates and agglomerants is analyzed for the production of concrete used in paving concrete blocks. Resistance, abrasion, water absorption and MEV are assessed. Replacement rates were fixed at $25 \%$ of heavy ash by small aggregates and up to $10 \%$ of light ash by Portland cement. Material was characterized by physical assay and pozolanic activity. A $25 \%$ replacement of small aggregates by heavy ashes and $2.5 \%$ of Portland cement by light ashes complied with ABNT NBR 9781:2013 recommendations.

KEY WORDS: Ashes from sugarcane bagasse; Mineral addition; Concrete block.

\section{INTRODUÇÃO}

O concreto de cimento Portland é um dos materiais mais utilizados pelo homem na construção civil, com um consumo de até 19 milhões de toneladas por ano (MEHTA E MONTEIRO, 2014). As estimativas atuais de fabricação de cimento Portland no mundo chegam a 3,7 bilhões de toneladas por ano, e a produção interna no Brasil chega a 68,8 milhões de toneladas por ano, sendo a quinta produtora mundial (SNIC, 2012).

A indústria do cimento Portland contribui com mais de $7 \%$ de todo $\mathrm{CO}_{2}$ produzido pelo homem na terra (MALHOTRA, 2002), sendo que, para cada tonelada de cimento produzido, cerca de $1 \mathrm{t}$ de dióxido de carbono $\left(\mathrm{CO}_{2}\right)$ é emitida na atmosfera, além de outros gases prejudiciais (MEHTA, 2002).

Visando reduzir os impactos ambientais, as emissões de gases do efeito estufa e melhorar as propriedades dos materiais da construção civil, merece destaque, no Brasil, a incorporação de resíduos agroindustriais, motivada principalmente em razão do grande montante gerado anualmente, pela falta de um destino viável e principalmente pelos resultados positivos, obtidos em estudos. Dentro desse contexto, destaca-se o plantio de cana-de-açúcar, que representa uma das principais atividades agrícolas do país, ocupando uma área de pouco mais de 9 milhões de 
hectares, por meio do qual o Brasil deverá produzir 654,6 milhões de toneladas de cana-de-açúcar na safra 2015/2016 (Conab, 2015) com uma produção que vem aumentando desde 2000, o que coloca o país em destaque no setor agroindustrial.

Como resultado final do processo produtivo das usinas sucroalcooleiras, grande quantidade de cinza, proveniente da queima do bagaço de cana (CBC), é gerada no Brasil, em torno de 4 milhões de toneladas por ano (aproximadamente 11 mil toneladas/dia) (UNICA, 2011). Em decorrência do avanço do setor na geração de energia, álcool e açúcar, a produção vem se intensificado.

Segundo dados do Fiesp/Ciesp (2001), para cada tonelada de cana-de-açúcar moída, geram-se $260 \mathrm{~kg}$ de bagaço e, para cada tonelada de bagaço queimado, geramse $24 \mathrm{~kg}$ de cinza. Geralmente essas cinzas são utilizadas como adubo nas plantações, mas, segundo pesquisas realizadas pela Embrapa, aquelas não possuem nutrientes minerais adequados para essa finalidade, pois há uma séria deficiência em potássio, principal nutriente para o plantio de cana-de-açúcar (LIMA et al., 2012). A indústria da cana-de-açúcar ainda está buscando soluções para eliminar os resíduos gerados em seu processo produtivo, sabendo que a cinza remanescente, após a queima do bagaço, é o último resíduo da cadeia produtiva e poderia ter um fim mais nobre por suas características físicas e químicas.

Estudos apontam que a cinza do bagaço de cana-de-açúcar (MARTIRENA HERNÁNDEZ et al., 1998; SINGH et al., 2000; PAYÁ et al., 2002 apud CORDEIRO, 2006), em virtude da presença predominante de sílica na composição química, apresenta-se como matéria-prima potencial na produção de cimentos compostos e de aditivos minerais para pastas, argamassas e concretos. Essas características resultam em benefícios na reologia, na resistência, na durabilidade e em outros fatores em decorrência do seu emprego (MALHOTRA; MEHTA, 1996; NEVILLE, 1997; MASSAZZA, 1998; SABIR et al., 2001; CORDEIRO, 2006).

Vale destacar que os aditivos minerais são substâncias adicionadas intencionalmente ao concreto, com os objetivos de reforçar e melhorar certas características da mistura e, além disso, facilitar também seu preparo, lançamento e utilização (PETRUCCI, 1995).

A capacidade produtiva da construção civil se deve a vários fatores, visto que é o setor com maior consumo de material na economia e, assim, tem maiores 
possibilidades de reciclar. Dentro dessa enorme variedade de materiais, sejam minerais, poliméricos ou metálicos, o consumo vem aumentando em diferentes graus de industrialização, para as mais diferentes aplicações e tipos de obras (SMITH, 1973; AGOPYAN, 1998; MATTOS; WAGNER, 1999 apud JOHN, 2000).

Ainda, segundo John (2000), esses materiais consumidos pelo setor da construção civil são em sua maioria compostos silicosos e sabe-se que a sílica é a espécie atômica mais comum no planeta. Assim, muitos resíduos de processos térmicos (como a cinza do bagaço de cana), metalúrgicos e de tratamento ambiental podem ser incorporados e reutilizados como substitutos de matérias industrializadas que consomem altas quantidades de recursos não renováveis.

Os materiais utilizados como substitutos do cimento são denominados de materiais pozolânicos que são classificados como um material inorgânico, natural ou artificial, silicoso ou alumino-silicoso, que pode apresentar propriedades aglomerantes, quando finamente moído e em presença de água e hidróxido de cálcio. O emprego de pozolana como material cimentício remonta à Antiguidade, desde as primeiras obras de engenharia, realizadas pelos romanos (CORDEIRO et al., 2009).

A aplicação das pozolanas como substitutas parciais de cimento Portland deve-se à presença de fases ativas em sua constituição química, só que, muitas vezes, na produção de $\mathrm{CBC}$, dependendo do controle operacional de queima do bagaço, essa cinza acaba possuindo pouca reatividade, sendo uma alternativa, assim, sua aplicação em substituição de agregados miúdos (areia natural) na composição do concreto (CORDEIRO et al., 2008; SOUZA et al., 2007). As alternativas de substituição da areia natural são de grande importância, pois diminuem sua extração de forma irregular e em grandes quantidades, evitando, assim, a degradação do ecossistema local.

Com base no que foi relatado, este trabalho busca caracterizar e analisar a aplicação da cinza proveniente da queima do bagaço de cana-de-açúcar, para determinar a possibilidade, ou não, de sua aplicação na substituição parcial do cimento Portland e do agregado miúdo na confecção de concreto para produção de blocos intertravados para pavimentação. 


\section{MATERIAL E MÉTODO}

Nos últimos anos, um novo material tem sido alvo de pesquisas com vistas ao aproveitamento como pozolana, ou em substituição ao agregado miúdo, empregado em conjunto com o concreto de cimento Portland, trata-se da cinza do bagaço de cana-de-açúcar. De acordo com suas propriedades, pode-se definir a cinza como um material com a pozolanicidade suficiente para contribuir com a mistura cimentícia, ou um material com baixa pozolanicidade e inerte, classificando-a como cinza leve e cinza pesada, respectivamente.

Pode-se entender como material pozolânico todo material inorgânico, natural ou artificial, silicoso ou alumino-silicoso que por si só não apresenta atividade hidráulica, no entanto, quando finamente moído e em presença de água, a temperatura ambiente, reage com o hidróxido de cálcio, formando compostos com propriedades cimentícias, e isso vale tanto para a pozolana natural, como para a artificial (ACI 116.R-00, 2002). Para a cinza classificada com baixa atividade pozolânica, cinza pesada, esta apresenta propriedades próximas à da areia natural, possuindo uma estrutura cristalina bem definida e com presença predominante de quartzo.

A cinza do bagaço de cana-de-açúcar utilizada é proveniente de uma usina termoelétrica da região de Maringá/PR, região com alta concentração de usinas e oferta de cinza.

Após a queima do bagaço, é possível a obtenção da cinza que cai embaixo da fornalha, com predomínio de cinza pesada. Antes da aplicação como substituto da areia, ela foi peneirada entre as malhas $0,6 \mathrm{~mm}$ para a retirada de pequenas partículas, resultante da combustão incompleta na Figura 1. 


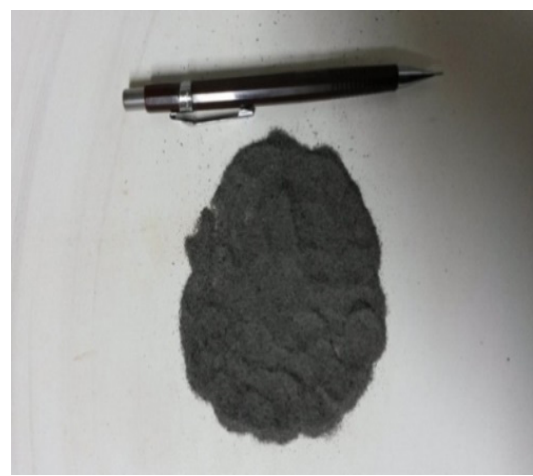

Figura 1. Cinza pesada do bagaço de cana-de-açúcar.

A análise granulométrica foi realizada pela combinação entre peneiramento e sedimentação, seguindo a ABNT NBR 7181:1984. A Tabela 1 retrata as porcentagens retidas e sua classificação.

Tabela 1. Classificação granulométrica da cinza pesada

\begin{tabular}{c|c}
\hline Classificação segundo a ABNT NBR 6502:1995 & Percentagem retida (\%) \\
\hline 0,6 a $2 \mathrm{~mm}$ (Areia grossa) & 0 \\
\hline 0,2 a $0,6 \mathrm{~mm}$ (Areia média) & 46 \\
\hline 0,06 a $0,2 \mathrm{~mm}$ (Areia fina) & 51 \\
\hline 0,002 a $0,06 \mathrm{~mm}$ (Silte) & 2,5 \\
\hline$\leq 0,002 \mathrm{~mm}$ (Argila) & 0,5 \\
\hline
\end{tabular}

Verifica-se que mais de $50 \%$ da amostra ficaram retidos nas peneiras de 0,06 a 0,2 mm e, de acordo com a classificação da ABNT NBR 6502:1995, são semelhantes à areia fina e apresentaram massa específica, próxima à massa específica da areia utilizada, de $2,75 \mathrm{~g} / \mathrm{cm}^{3}$.

$\mathrm{O}$ índice de atividade pozolânica pelo método Chapelle foi realizado, seguindo-se a ABNT NBR 15895:2010, e o valor obtido foi de $101 \mathrm{mg} \mathrm{Ca}(\mathrm{OH}) 2 / \mathrm{g}$ amostra. Esse resultado é menor que o valor mínimo exigido pela ABNT NBR 15895:2010, de $436 \mathrm{mg} \mathrm{Ca}(\mathrm{OH}) 2 / \mathrm{g}$ amostra, portanto, este ensaio permite afirmar que a cinza pesada não possui quantidade mínima de $\mathrm{Ca}(\mathrm{OH}) 2$ para ser classificada como pozolânica. 


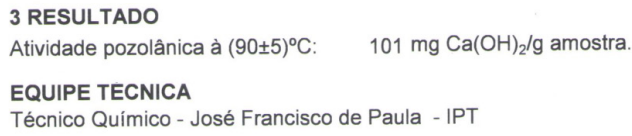

São Paulo, 27 de Agosto de 2014.
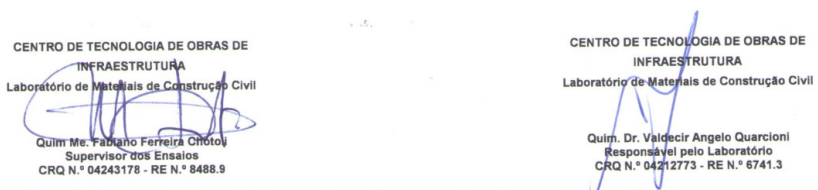

Figura 2. Ensaio de atividade pozolânica.

A cinza leve utilizada é obtida pela usina por um mecanismo que permite que o material volante seja arrastado junto aos gases de exaustão e retirado por lavadores de gases que utilizam um circuito fechado de água, sendo assim, as partículas sólidas são transferidas para o meio líquido e separadas.

Antes do armazenamento, a cinza foi peneirada na malha $425 \mu \mathrm{m}$ para retirada de partículas provenientes da combustão incompleta (Figura 3).

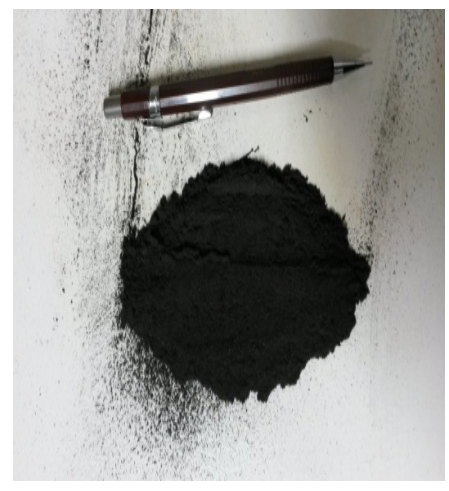

Figura 3. Cinza leve.

A análise granulométrica da cinza leve permitiu sua classificação, sendo apresentadas, na Tabela 2, as porcentagens retidas. 
Tabela 2. Classificação granulométrica da cinza leve

\begin{tabular}{c|c}
\hline Classificação segundo a ABNT NBR 6502:1995 & Percentagem retida (\%) \\
\hline 0,6 a $2 \mathrm{~mm}$ (Areia grossa) & 0,5 \\
\hline 0,2 a $0,6 \mathrm{~mm}$ (Areia média) & 2 \\
\hline 0,06 a $0,2 \mathrm{~mm}$ (Areia fina) & 13,5 \\
\hline 0,002 a $0,06 \mathrm{~mm}$ (Silte) & 81 \\
\hline$\leq 0,002 \mathrm{~mm}$ (Argila) & 3 \\
\hline
\end{tabular}

Nota-se pela análise da tabela que mais de $50 \%$, ou seja, $81 \%$ da amostra, ficaram retidos nas peneiras de 0,002 a $0,06 \mathrm{~mm}$ e, de acordo com a classificação da ABNT NBR 6502:1995, são semelhantes ao silte.

$\mathrm{O}$ índice de atividade pozolânica, realizado segundo a ABNT NBR 15895:2010, foi de $569 \mathrm{mg} \mathrm{Ca}(\mathrm{OH}) 2 / \mathrm{g}$ amostra. Esse resultado é maior que o valor mínimo de consumo de $\mathrm{CaO}$ igual a $330 \mathrm{mg}$ por grama do material pozolânico (equivalente a $436 \mathrm{mg} \mathrm{Ca}(\mathrm{OH}) 2 / \mathrm{g}$ da amostra), valor proposto por Raverdy et al. (1980 apud Cordeiro 2006). Portanto, este ensaio permite afirmar que a cinza leve possui uma atividade pozolânica considerável, visto que a mesma será substituída parcialmente pelo cimento Portland.
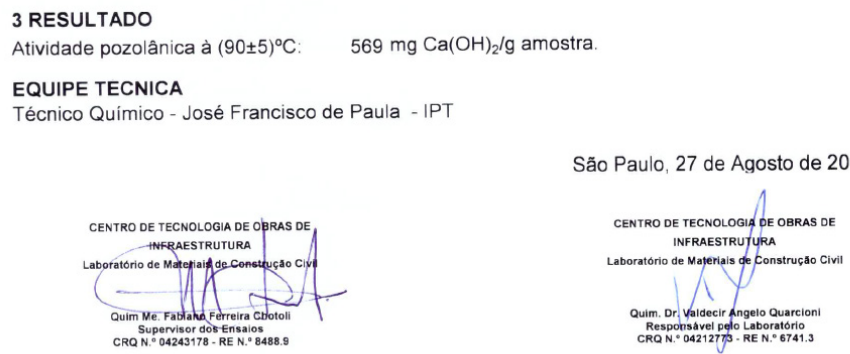

Figura 4. Ensaio de atividade pozolânica

Um requisito, previamente estabelecido para a escolha do cimento a ser utilizado para confecção dos blocos de concreto, foi a alta resistência nas primeiras 
idades pela necessidade de rápida desforma e transporte das peças, dessa forma, o cimento mais indicado é o CP V-ARI, regulamentado pela ABNT NBR 5733:1991. Esse aglomerante é recomendado pela ABCP (2002) no preparo de elementos prémoldados de concreto e artefatos de cimento, como em fábricas de blocos para alvenaria, blocos para pavimentação, lajes, meio-fio e outros. Esse cimento possui uma dosagem diferente de calcário e argila na produção do clínquer e uma moagem mais fina. O cimento empregado na fabricação dos blocos foi o cimento Portland CP V - ARI.

O agregado miúdo, utilizado na fabricação das peças pré-moldadas, foi a areia média natural quartzosa, obtida por fornecedores da região de Maringá/PR.

Esse foi caracterizado de acordo com os ensaios descritos nas seguintes normas: determinação da composição granulométrica: ABNT NBR NM 248:2003 "Agregados - determinação da composição granulométrica"; determinação da massa unitária: ABNT NBR NM 45:2006 "Agregados - Determinação da massa unitária e do volume de vazios"; determinação da massa específica: ABNT NBR NM 52:2009 "Agregado miúdo - Determinação de massa específica e massa específica aparente".

Tabela 3. Caracterização do agregado miúdo

\begin{tabular}{l|c|c}
\hline \multicolumn{1}{c|}{ Característica Analisada } & Unidade & Valores \\
\hline Massa específica & $\mathrm{g} / \mathrm{cm}^{3}$ & 2,65 \\
\hline Massa unitária no estado solto & $\mathrm{g} / \mathrm{cm}^{3}$ & 1,52 \\
\hline Volume de vazios & $\%$ & 42,6 \\
\hline Módulo de finura & - & 1,80 \\
\hline Dimensão máxima caraterística & $\mathrm{mm}$ & 1,20 \\
\hline
\end{tabular}

O agregado graúdo natural empregado foi a brita zero, de origem basáltica, também encontrada sob a denominação comercial de pedrisco, possuindo diâmetro predominante entre 4,8 e 9,5 mm. Foram realizados ensaios descritos nas seguintes normas: ABNT NBR NM 248:2003, ABNT NBR NM 45:2006; ABNT NBR NM 53:2009. A Tabela 4 apresenta os resultados do ensaio. 
Tabela 4. Caracterização do agregado graúdo

\begin{tabular}{l|c|c}
\multicolumn{1}{c|}{ Característica analisada } & Unidade & Valores \\
\hline Massa específica & $\mathrm{g} / \mathrm{cm}^{3}$ & 2,90 \\
\hline Massa unitária no estado solto & $\mathrm{g} / \mathrm{cm}^{3}$ & 1,51 \\
\hline Volume de vazios & $\%$ & 47,9 \\
\hline Módulo de finura & - & 5,00 \\
\hline Dimensão máxima caraterística & $\mathrm{mm}$ & 9,50 \\
\hline
\end{tabular}

Para a avaliação dos blocos de concreto, as variáveis analisadas estão relacionadas com suas características técnicas e de desempenho, inerentes às solicitações a que esse tipo de pavimento está sujeito.

Pelo fato de serem produtos utilizáveis em vias de tráfego, deve-se considerar que estes estão submetidos a esforços de compressão, sua superfície também está sujeita à ação da abrasão pelo, e sua durabilidade está indiretamente ligada à absorção de água. Sendo assim, foram definidas as variáveis que caracterizam o seu desempenho técnico:

- resistência à compressão;

- absorção de água;

- resistência à abrasão;

- análise da microestrutura do concreto (MEV).

Os blocos de concreto receberam o ciclo de cura natural, por um período de $24 \mathrm{~h}$, em que a cura foi realizada em condições ambientes, protegida das intempéries. Posteriormente, os pavers foram colocados em câmara úmida onde permaneceram até a data dos ensaios, com 28 dias.

A Tabela 5 retrata a programação esquemática envolvendo os parâmetros de execução dos experimentos, bem como o número de blocos de concreto que foram moldados e utilizados para cada ensaio. Nota-se que o teor de substituição da cinza pesada foi previamente definido em $25 \%$, por estudos já realizados por MARTINS e ALTOÉ (2015), onde se constatou o melhor desempenho. 
Tabela 5. Planejamento experimental

\begin{tabular}{c|c|c}
\hline \multicolumn{2}{l}{ Teor de substituição (\%) } \\
\hline Traço & Cinza leve & Cinza pesada \\
\hline T1 & 0,0 & 0,0 \\
\hline T2 & 0,0 & 25,0 \\
\hline T3 & 2,5 & 25,0 \\
\hline T4 & 5,0 & 25,0 \\
\hline T5 & 7,5 & 25,0 \\
\hline T6 & 10,0 & 25,0 \\
\hline
\end{tabular}

Segundo Pagnussat (2004), durante a confecção do concreto, por não existir um teste de consistência ou trabalhabilidade específico, foi utilizado para definir a melhor quantidade de água o método do "Ponto de Pelota", verificando a consistência, se a pelota se firmava nas mãos ou se soltava, definindo, assim, se era necessário aumentar ou diminuir a quantidade de água, como se nota na Figura 5.

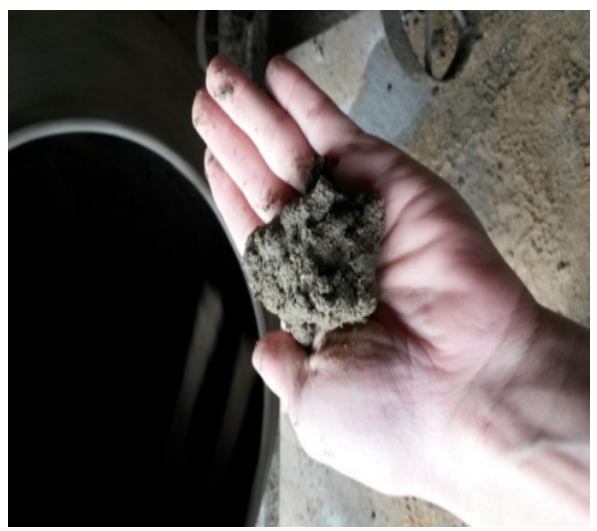

Figura 5. Determinação do "Ponto de Pelota".

O traço definido é da ordem de 1:4, com consumo de cimento de 437,03 $\mathrm{kg} / \mathrm{m}^{3}$. A Figura 6 mostra o aspecto do bloco de concreto confeccionado. A forma e as dimensões das peças fabricadas ficaram condicionadas ao molde da vibro-prensa utilizada, com formato retangular e com 19,5x9,5x8,0 cm. 


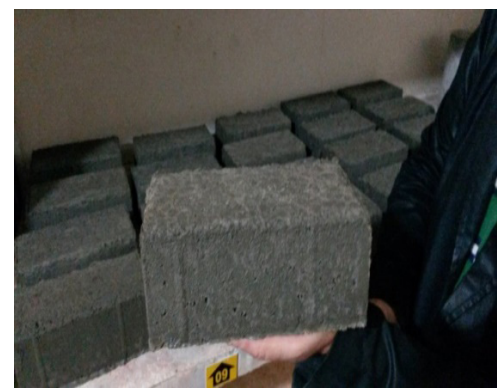

Figura 6. Bloco de concreto intertertravado.

O ensaio seguiu o estabelecido na ABNT NBR 9781:2013- "Peças de concreto para pavimentação - Especificação e métodos de ensaio". Os pavers foram capeados com enxofre e ensaiados na prensa de resistência à compressão, disponibilizada pelo Laboratório de Engenharia Civil/UEM, uma Máquina Universal de Ensaios, da marca EMIC.

Para a realização do ensaio, deveriam ser colocadas duas placas de aço centralizado na prensa, com diâmetro de $(85+0,5) \mathrm{mm}$ e espessura mínima de $20 \mathrm{~mm}$, simulando, assim, o esforço que o paver deveria suportar durante o seu emprego.

O procedimento adotado seguiu a ABNT NBR 9781:2013- "Peças de concreto para pavimentação - Especificação e métodos de ensaio", que se inicia com a preparação do corpo de prova, removendo todo o pó, utilizando-se uma escova. Para o ensaio, foram utilizados quatro blocos de concreto para cada traço na idade de 28 dias.

A resistência dos blocos de concreto à abrasão está diretamente ligada à resistência do pavimento ao desgaste provocado pela circulação de veículos e pedestres, sendo uma importante análise de sua vida útil. É um ensaio facultativo e os estudos utilizam várias metodologias para a realização daquele.

O ensaio utilizado para a determinação da abrasão foi o método CIENTEC, disponibilizado pela Fundação de Ciência e Tecnologia do Estado do Rio Grande do Sul. Foram ensaiados os pavers que apresentassem melhor desempenho e o traço de referência para efeito comparativo.

O método Cientec consiste em simular um percurso de $500 \mathrm{~m}$, percorridos pelo corpo de prova, com uma pressão constante de 0,06 MPa sobre pó abrasivo 
carborundo. O resultado é obtido com a realização de medições em cinco pontos do corpo de prova antes e após a realização do ensaio, sendo o índice de desgaste a média dessas medições e dado em mm. Para a realização do ensaio, são extraídas duas amostras de cada paver com serra diamantada com as dimensões de 50x50mm.

O ensaio de MEV foi realizado no Complexo de Centrais de Apoio à Pesquisa (COMCAP), da Universidade Estadual de Maringá/PR, por meio de microscópio eletrônico de varredura de elétrons Superscan SS - 550, da marca Shimadzu, operando com tensão de aceleração de $10 \mathrm{kV}$, com capacidade de aumento de 60 a 6.000 vezes, para fazer a caracterização da sua microestrutura, analisando os principais compostos da matriz cimentícia.

\section{RESULTADOS}

Seguindo o previsto na ABNT NBR 9781:1987, os pavers fabricados com diferentes teores de substituição foram ensaiados à compressão, a fim de determinar a resistência característica para cada traço. Os resultados dos ensaios constam na Tabela 6.

Tabela 6. Resistência à compressão característica

\begin{tabular}{c|c|c|c}
\hline \multicolumn{3}{|c|}{ TEOR DE SUBSTITUIÇÃO } & 28 dias \\
\hline \multirow{2}{*}{ TRAÇO } & CINZA LEVE & CINZA PESADA & $\mathrm{F}_{\mathrm{pk}}$ \\
\hline T1 & 0,0 & 0,0 & 31,16 \\
\hline T2 & 0,0 & 25,0 & 37,08 \\
\hline T3 & 2,5 & 25,0 & 35,04 \\
\hline T4 & 5,0 & 25,0 & 27,03 \\
\hline T5 & 7,5 & 25,0 & 24,50 \\
\hline T6 & 10,0 & 25,0 & 24,63 \\
\hline
\end{tabular}

Os traços que apresentaram desempenho satisfatório foram T2 e T3, sendo que a incorporação apenas com cinza pesada (T2) teve um aumento considerável 
em relação ao traço de referência, permitindo relatar que a cinza pesada melhora as propriedades mecânicas do concreto ao ser substituída pelo agregado miúdo (no teor de 25\%). Quando se substituíram 2,5\% de cinza leve pelo cimento Portland (T3), notou-se uma redução da resistência, porém ainda maior que o traço de referência (T1), visto que o material $(\mathrm{CBC})$ possui atividade pozolânica mas não igual à do cimento Portland.

Conforme os teores de cinza leve foram aumentando, pode-se dizer que a resistência diminuiu em relação ao traço T2, pela crescente retirada de cimento Portland, mas ainda são consideráveis os valores obtidos, e, dependendo da aplicação dada para estes, o concreto apresentará ótimo desempenho. Vale destacar que no T6 houve um pequeno ganho de resistência, podendo estar relacionado ao aumento de teor de finos e consequente maior densidade de empacotamento, em que há diminuição do volume de vazios, resultando, possivelmente, num melhor desempenho do concreto.

A absorção de água dos pavers foi determinada para a idade de 28 dias. Os resultados obtidos nos ensaios constam da Tabela 7 .

Tabela 7. Absorção de água

\begin{tabular}{c|c|c|c}
\hline \multicolumn{3}{|c|}{ Teor de substituição (\%) } & 28 dias \\
\hline Traço & Cinza leve & Cinza pesada & Absorção (\%) \\
\hline T1 & 0,0 & 0,0 & 4,45 \\
\hline T2 & 0,0 & 25,0 & 5,60 \\
\hline T3 & 2,5 & 25,0 & 3,20 \\
\hline T4 & 5,0 & 25,0 & 5,59 \\
\hline T5 & 7,5 & 25,0 & 6,03 \\
\hline T6 & 10,0 & 25,0 & 6,58 \\
\hline
\end{tabular}

Nota-se que os traços T1, T2, T3 e T4 estão dentro dos limites da ABNT NBR 9781:2013 para absorção. Não houve regularidade nos resultados, e vale ser destacado que os três traços iniciais dos blocos de concreto moldados apresentaram melhor aparência e uma superfície mais lisa, talvez isso possa influenciar na absorção. 
No traço T3 houve menor absorção, podendo estar relacionada ao fechamento dos vazios existentes no concreto, e, posteriormente, nota-se um aumento da absorção no T4, T5 e T6, que pode estar ligado à má compactação do bloco de concreto na vibro-prensa.

O ensaio de resistência à abrasão foi realizado para todos os traços, sendo realizado um exemplar para cada traço. Os dados constam na Tabela 8.

Tabela 8. Resistência à abrasão

\begin{tabular}{c|c|c|c}
\hline \multicolumn{3}{c|}{ Teor de substituição (\%) } & Resistência à abrasão \\
\hline Traço & Cinza leve & Cinza Pesada & Índice de desgaste $(\mathrm{mm})$ \\
\hline $\mathrm{T} 1$ & 0,0 & 0,0 & 5,77 \\
\hline $\mathrm{T} 2$ & 0,0 & 25,0 & 5,26 \\
\hline $\mathrm{T} 3$ & 2,5 & 25,0 & 5,33 \\
\hline $\mathrm{T} 4$ & 5,0 & 25,0 & 5,57 \\
\hline $\mathrm{T} 5$ & 7,5 & 25,0 & 6,68 \\
\hline $\mathrm{T} 6$ & 10,0 & 25,0 & 7,38 \\
\hline
\end{tabular}

Nota-se que os índices de desgaste por abrasão para os traços T2, T3 e T4 com substituição de cinza foram inferiores ao traço de referência, assim, a incorporação de cinza contribuirá para maior conservação e menor desgaste que o paver venha a sofrer.

Nota-se que no T2 houve menor desgaste à abrasão, podendo se correlacionar com os resultados de absorção e resistência à compressão que foram os melhores, tornando clara a viabilidade de substituição de cinza pesada pelo agregado graúdo, melhorando sua durabilidade. $\mathrm{O}$ mesmo se destaca para o T3 que também apresentou bom desempenho em relação ao traço de referência. Conforme o teor de cinza leve aumentou, o desgaste à abrasão também aumentou, verificando-se que a cinza leve não minimiza o desgaste, embora os valores obtidos ainda sejam consideráveis As micrografias das amostras de concreto foram coletadas no ensaio de resistência à compressão com idade de 28 dias, com a indicação dos compostos principais que formam o concreto: silicato de cálcio hidratado, etringita e portlandita. 
As figuras abaixo apresentam a matriz cimentícia, aumentada 3.000x para o traço de referência (T1), o traço de melhor desempenho mecânico (T2), o traço com adição 2,5\% de cinza leve (T3) e o considerado de pior desempenho mecânico (T6), para o concreto estudado.

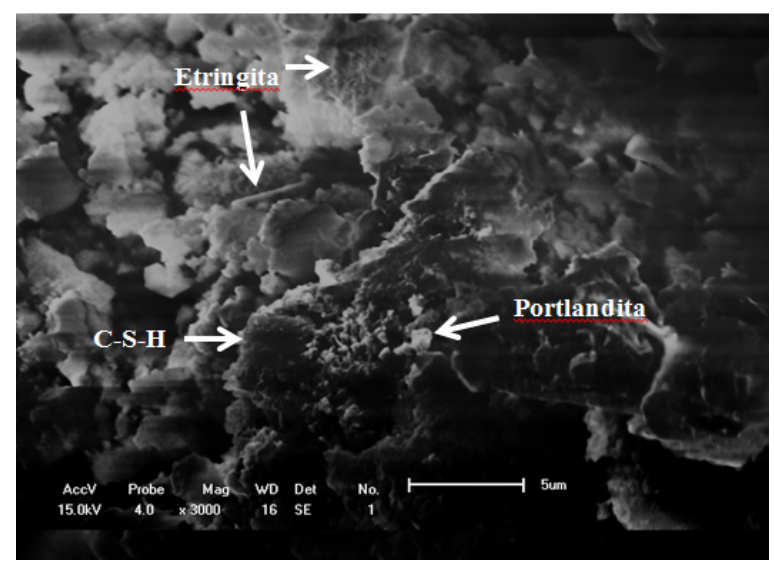

Figura 7. Micrografia do concreto de traço 1.

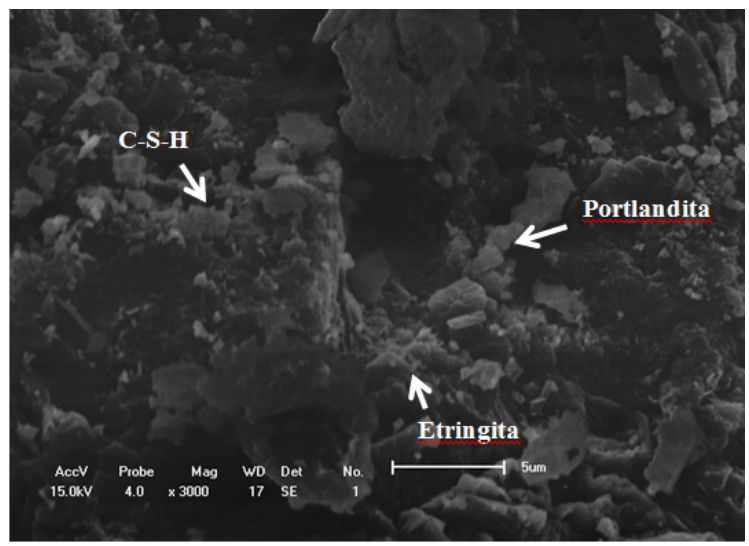

Figura 8. Micrografia do concreto de traço 2. 


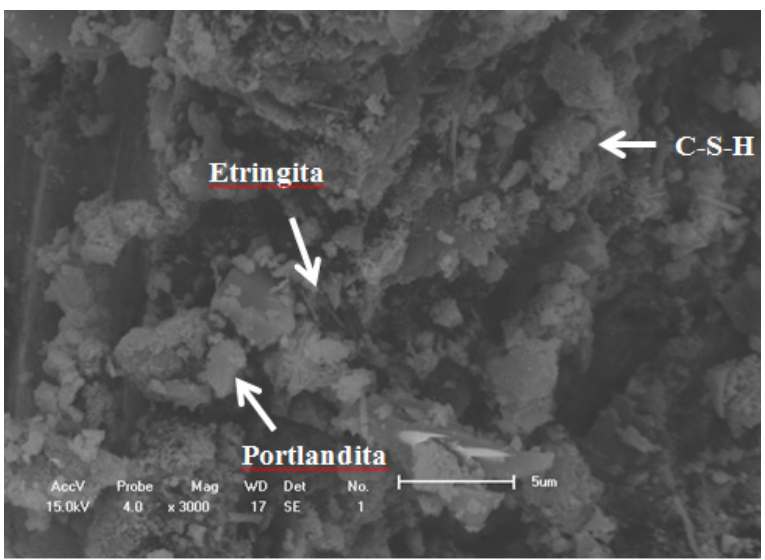

Figura 9. Micrografia do concreto de traço 3.

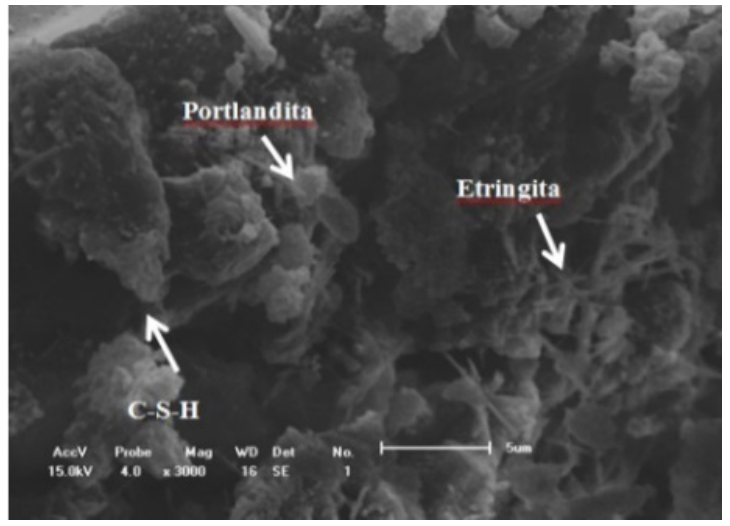

Figura 10. Micrografia do concreto de traço 6.

Ao se analisar a microscopia do concreto com os diferentes traços, há uma pequena indicação de que o silicato de cálcio hidratado diminuiu com a maior substituição do cimento, e este é o principal composto resultante da hidratação do cimento Portland, responsável pela resistência mecânica. Observa-se, também, a reduzida quantidade de etringita nos traços 1, 2 e 3 em relação ao traço 6. Os cristais da etringita são os primeiros a se formarem no processo de hidratação do cimento e contribuem para redução na resistência mecânica e aumento de fissuras, levando o concreto a uma maior deterioração. 


\section{CONSIDERAÇÕES FINAIS}

Pode-se concluir que há viabilidade na substituição de até 2,5\% de cimento Portland por cinza leve e de $25 \%$ de agregado miúdo por cinza pesada. O traço com essas substituições atingiu resistência mecânica à compressão superior ao mínimo recomendado pela norma de $35 \mathrm{MPa}$, absorção de água menor que o limite máximo da norma, desgaste por abrasão inferior ao traço referência. Vale destacar que, ao se analisar a microscopia do concreto com os diferentes traços, há indicação de que houve diminuição do silicato de cálcio hidratado à medida que ocorreu maior substituição do cimento, com aumento da etringita.

\section{REFERÊNCIAS}

ABCP - Associação Brasileira de Cimento Portland, 2002. Guia básico de utilização do cimento Portland - BT-106. 7 ed. São Paulo: ABCP, 28 p.

ASSOCIAÇÃO BRASILEIRA DE NORMAS TÉCNICAS. NBR NM 45. Agregados Determinação da massa unitária e do volume de vazios. Rio de Janeiro, 2006.

ASSOCIAÇÃO BRASILEIRA DE NORMAS TÉCNICAS. NBR NM 52. Agregado miúdo - Determinação de massa específica e massa específica aparente. Rio de Janeiro, 2009.

ASSOCIAÇÃO BRASILEIRA DE NORMAS TÉCNICAS. NBR NM 53. Agregado graúdo - determinação de massa específica, massa específica aparente e absorção de água. Rio de Janeiro, 2009.

ASSOCIAÇÃO BRASILEIRA DE NORMAS TÉCNICAS. NBR NM 248. Agregados Determinação da composição granulométrica. Rio de Janeiro, 2003.

ASSOCIAÇÃO BRASILEIRA DE NORMAS TÉCNICAS. NBR 15895. Materiais pozolânicos - Determinação do teor de hidróxido de cálcio fixado - Método Chapelle modificado. Rio de Janeiro, 2010. 
ASSOCIAÇÃO BRASILEIRA DE NORMAS TÉCNICAS. NBR NM 9781. Peças de concreto para pavimentação- Especificação e métodos de ensaio. Rio de Janeiro, 2013.

CONAB, Acomp. safra Bras. cana-de-açúcar, v. 1 - Safra 2014/15. n.2 - Segundo Levantamento. Brasília, p. 1-20, ago. 2014

CORDEIRO, G. C. Utilização de cinzas ultrafinas do bagaço de cana-de-açúcar e da casca de arroz como aditivos minerais em concreto. Tese (Doutorado em Engenharia Civil)- Universidade Federal do Rio de Janeiro, Rio de Janeiro, 2006.

CORDEIRO, G. C.; TOLEDO FILHO, R. D.; FAIRBAIRN, E. M. R. Caracterização de cinza do bagaço de cana-de-açúcar para emprego como pozolana em materiais cimentícios. Quím. Nova [online]., v. 32, n. 1, p. 82-86, 2009.

CORDEIRO, G. C.; TOLEDO FILHO, R. D.; TAVARES, L. M.; FAIRBAIRN, E. M. R. Pozzolanic activity and filler effect of sugar cane bagasse ash in Portland cement and lime mortars.Cement and Concrete Composites, v. 30, p. 410-418, 2008.

FIESP/CIESP, Ampliação da oferta de energia através da biomassa (bagaço da cana-de-açúcar). São Paulo: FIESP/CIESP, 2001. p. 90.

GARTNER, E. M. Industrially interesting approaches to 'low-CO2' cements, Cement and Concrete Research, v. 34, n. 9, pp. 1489-1498, 2004.

JOHN, V. M. Reciclagem de resíduos na construção civil: Contribuição para metodologia de pesquisa e desenvolvimento. 2000. 113f. Tese (Livre Docência) Escola Politécnica da Universidade de São Paulo, Departamento de Engenharia de Construção Civil, São Paulo, SP.

LIMA, S. A.; HUMBERTO, V.; SALES, A.; NETO, V.F. Analysis of the mechanical properties of compressed earth block masonry using the sugarcane bagasse ash. Construction \& Building Materials, v. 35, p. 829-837, 2012.

MARTINS, C. H.; ALTOÉ, S. P. S. Avaliação da utilização da cinza de bagaço de canade-açúcar na confecção de blocos de concreto para pavimentação. Revista em Agronegócio e Meio ambiente, Maringá (PR), v. 8, p. 39-54, 2015. 
MALHOTRA, V. M., MEHTA, P. K. Pozzolanic and cementitious materials. Amsterdam: Gordon and Breach Publishers, 2001. 191 p.

MALHOTRA, V. M. Introduction: sustainable development and concrete technology, Concrete International, v. 24, n. 7, pp. 22, 2002.

MASSAZZA, F. Pozzolana and pozzolanic cements. In: HEWLETT, P. C. (Ed.). Lea's chemistry of cement and concrete. 4. ed. New York: J. Wiley, 1998. p. 471-631.

MEHTA, P. K. Greening of the concrete industry for sustainable development. Concrete International, v. 24, n. 7, p. 23-28, 2002.

MEHTA, P.K.; MONTEIRO, P.J.M. Concreto: Estrutura, propriedades e materiais. São Paulo: Ibracon, 2014. 751p.

PAGNUSSAT, D. Utilização de Escória Granulada de Fundição em Blocos de Concreto para Pavimentação. 2004. Dissertação (Mestrado) - PPGEC/UFRGS, Porto Alegre, RS.

PETRUCCI, E. G. R. Concreto de cimento Portland. 13. ed. São Paulo: [s.n.], 1995.

SABIR, B. B.; WILD, S.; BAI, J. Metakaolin and calcined clays as pozzolans for concrete: a review. Cement and Concrete Research, v. 23, n. 2, p. 441-454, 2001.

SOUZA, G.N.; FORMAGINI, S.; CUSTÓDIO, F.O.; SILVEIRA, M.M. Desenvolvimento de argamassas com substituição parcial do cimento Portland por cinzas residuais do bagaço de cana-de-açúcar. In: CONGRESSO BRASILEIRO DO CONCRETO, 49., 2007. Anais... São Paulo: IBRACON, 2007.

UNICA - União da Indústria de Cana-de-Açúcar, 2011. Bagaço de cana pode ganhar valor substituindo areia na construção civil. Disponível em: <http://www. unica.com.br/noticia/33630022920327850689/bagaco-de-cana-pode ganhar-valorsubstituindo-areia-na-construcao-civil/> . Acesso em: 09 mar. 2015.

Recebido em: 04 de abril de 2016 Aceito em: 12 de maio de 2017 